\title{
Predictors of successful clinical and laboratory outcomes in patients with primary sclerosing cholangitis undergoing endoscopic retrograde cholangiopancreatography
}

\author{
R Enns MD FRCP ${ }^{1}$, MA Eloubeidi MHS MD ${ }^{2,3}, \mathrm{~K}$ Mergener $\mathrm{MD}^{2}$, PS Jowell MB ChB ${ }^{2}$, \\ MS Branch MD², J Baillie MB ChB FRCP2
}

\begin{abstract}
R Enns, MA Eloubeidi, K Mergener, PS Jowell, MS Branch, J Baillie. Predictors of successful clinical and laboratory outcomes in patients with primary sclerosing cholangitis undergoing endoscopic retrograde cholangiopancreatography. C an J G astroenterol 2003;17(4):243-248.
\end{abstract}

Endoscopic retrograde cholangiopancreatography (ERCP) in patients with primary sclerosing cholangitis (PSC) can be a challenging and sometimes gratifying opportunity for therapeutic intervention. A Ithough there often appears to be initial radiological improvement after ERC $P$, the benefit as measured by serial estimations of subsequent liver enzymes is questionable. The fluctuating course of the inflammatory process makes the interpretation of serology even more difficult.

OBJECTIVES: To document and compare the liver profile and clinical status of patients before and after diagnostic and therapeutic ERCP; to determine predictors of clinical and laboratory success in patients with PSC; and to assess the complication rate of diagnostic and therapeutic ERCP in these patients.

METHODS: All patients with PSC who underwent ERCP at the authors' medical centres between January 6, 1987 and January 12, 1998 were identified using a computerized database. Presenting symptoms, liver enzymes (aspartate aminotransferase, alanine aminotransferase, alkaline phosphatase) and bilirubin were recorded before ERCP. Clinical success was defined as resolution of the presenting symptoms. Laboratory success was defined as improvement in two of three liver enzymes by at least $50 \%$, or resolution of jaundice.

RESU LT S: O ne hundred four patients underwent 204 ERCPs of which 56 ER C Ps were diagnostic. Clinical improvement was seen in $35 \%$ of the patients after diagnostic ERCP and in 70\% after therapeutic procedures $\left(\chi^{2}=18.4, P=0.001\right)$. Laboratory improvement was seen in $35 \%$ of patients undergoing diagnostic ERCP and in $52 \%$ of the patients undergoing therapeutic ERCP $(P=0.04)$. The reductions in liver enzymes were significant in both the diagnostic and therapeutic groups. Serum bilirubin level decreased significantly in the therapeutic ERCP group only. In a univariate analysis, patients with common bile duct strictures, any dominant stricture and those who underwent a therapeutic procedure were most likely to have clinical and laboratory improvement. In multivariable logistic regression, the presence of a dominant stricture, endoscopic therapy and high serum bilirubin were all independent predictors of a successful clinical outcome. There was no difference in total complication rates ( $18 \%$ versus $14 \%$ ) when comparing the diagnostic and therapeutic ERCP groups. However, all seven severe complications occurred in the therapeutic ERCP group.

C O N C LU SIO N S: First, in PSC, clinical and laboratory improvement is more common in patients undergoing therapeutic ERCP than diagnostic ERCP. Second, aspartate aminotransferase, alanine aminotransferase and alkaline phosphatase improve following both diagnostic and therapeutic $E R C P$, and should therefore not be relied upon to determine the success of the procedure. Third, bilirubin levels decreased in the therapeutic group but remained unchanged in the diagnostic group, suggesting that the serum bilirubin level may be a more sensitive indicator of successful therapeutic intervention than transaminases. Fourth, common bile duct strictures, dominant strictures and bilirubin levels are important variables in determining the success of an ERCP in PSC. Finally, complication rates after therapeutic ERCP are similar to those after diagnostic ERCP in PSC patients. However, severe complications occur more commonly in the therapeutic group.

Key W ords: Biliary tract; Endoscopic outcomes; ERC P; Sclerosing cholangitis

\section{Les prédicteurs d'issues cliniques et de labora- toire positives chez les patients atteints d'an- giocholite sclérosante primitive qui subissent une cholangiopancréatographie rétrograde endoscopique}

Chez les patients atteints d'angiocholite sclérosante primitive (A SP), la cholangiopancréatographie rétrograde endoscopique (CPRE) peut constituer une occasion redoutable et parfois gratifiante de procéder à une intervention thérapeutique. Bien qu'une amélioration radiologique semble souvent suivre une CPRE, les avantages mesurés d'après les évaluations sérielles de enzymes hépatiques sont douteux. L'évolution irrégulière du processus inflammatoire rend l'interprétation de la sérologie encore plus complexe.

OBJECTIFS : Documenter et comparer le profil hépatique et le statut clinique des patients avant et après la CPRE diagnostique ou thérapeutique. Déterminer les prédicteurs d'issues cliniques et de laboratoire positives chez les patients atteints d'A SP. Évaluer le taux de complications des CPRE diagnostique et thérapeutique chez ces patients.

MÉTH ODOLOGIE : Tous les patients atteints d'A SP qui ont subi une CPRE aux centres médicaux des auteurs entre le 6 janvier 1987 et le 12 janvier 1998 ont été dépistés au moyen d'une base de données informatisée. Les manifestations initiales, les enzymes hépatiques (sérum glutamo-oxalacétique transaminase, sérum glutamopyruvique transaminase, phosphatase alcaline) et le taux de bilirubine ont été pris en note avant la

${ }^{1}$ St Paul's H ospital, U niversity of of B ritish C olumbia, Vancouver, B ritish C olumbia; '2D ivision of G astroenterology, D epartment of M edicine, D uke U niversity M edical C enter; ${ }^{3} \mathrm{C}$ enter for $\mathrm{H}$ ealth Services Research and D evelopment, Veterans A ffairs $\mathrm{M}$ edical C enter, D urham, $\mathrm{N}$ orth Carolina, USA

Correspondence and reprints: Dr R Enns, St Paul's H ospital, U niversity of British C olumbia, Suite \#300 1144 Burrard Street, Vancouver,

B ritish C olumbia V6Z-2A 5. Telephone 604-688-7017, fax 604-689-2004, e-mail renns@interchange.ubc.ca

Received for publication July 9, 2002. A ccepted December 10, 2002 
CPRE. Le succès clinique était défini par la résolution des manifestations initiales. Q uant au succès de laboratoire, il était défini par l'augmentation de deux des trois enzymes hépatiques d'au moins $50 \%$ ou par la résolution de la jaunisse.

RÉSU LTAT S : Cent quatre patients ont subi 204 CPRE, dont 56 servaient à des fins diagnostiques. U ne amélioration clinique s'est observée chez $35 \%$ des patients après la CPRE diagnostique, et chez $70 \%$ de ceux après la CPRE thérapeutique ( $c 2=18,4 ; P=0,001)$. Par ailleurs, une amélioration de laboratoire s'est observée chez $35 \%$ des patients après la CPRE diagnostique, et chez $52 \%$ de ceux après la $C P R E$ thérapeutique $(P=0,04)$. Les diminutions des enzymes hépatiques étaient significatives tant au sein du groupe diagnostique que du groupe clinique. Le taux de bilirubine sérique n'avait diminué de manière significative qu'au sein du groupe ayant subi une CPRE thérapeutique. Dans le cadre d'une analyse univariée, les patients ayant présenté une constriction biliaire courante ou une constriction dominante ou ayant subi une intervention thérapeutique étaient plus susceptibles de présenter une amélioration clinique et de laboratoire. Selon une régression logistique multivariable, une constriction dominante, un traitement endoscopique et un taux de bilirubine sérique élevé constituaient tous des prédicteurs indépendants d'issue clinique positive. On ne remarquait aucune différence dans le total des taux de complication (18\% par rapport à $14 \%$ ) lorsqu'on comparait le groupe ayant subi une CPRE diagnostique à celui ayant subi une CPRE thérapeutique. Cependant, les sept complications graves se sont produites au sein du groupe ayant subi une CPRE thérapeutique.

C ON C LU SION S: Premièrement, en cas d'A SP, une amélioration clinique et de laboratoire est plus courante chez les patients subissant une CPRE thérapeutique qu'une CPRE diagnostique. Deuxièmement, les taux de sérum glutamo-oxalacétique transaminase, de sérum glutamopyruvique transaminase et de phosphatase alcaline s'amélioraient tant après la C PRE diagnostique qu'après la CPRE thérapeutique, et il ne faudrait donc pas s'y fier pour déterminer le succès de l'intervention. Troisièmement, le taux de bilirubine diminuait au sein du groupe thérapeutique, mais demeurait inchangé au sein du groupe diagnostique, ce qui laisse supposer que le taux de bilirubine sérique peut constituer un indicateur plus sensible d'intervention thérapeutique positive que les transaminases. $Q$ uatrièmement, les constrictions biliaires courantes, les constrictions dominantes est le taux de bilirubine sont des variables importantes pour déterminer le succès d'une CPRE en cas d'A SP. Enfin, le taux de complication après un CPRE thérapeutique est semblable à celui obtenu après une CPRE diagnostique chez les patients atteints d'A SP. Cependant, des complications graves se produisent surtout au sein du groupe thérapeutique.
P rimary sclerosing cholangitis (PSC) is a chronic, progressive, fibrosing condition of unknown etiology affecting the intrahepatic and extrahepatic bile ducts, and frequently culminating in secondary biliary cirrhosis (1-4). Despite the numerous medical and surgical therapies that have been tried, ursodeoxycholic acid and liver transplantation remain the main stays of therapy in select patients (5-14). A lthough it is a rare cause of liver disease (alcoholic liver disease is 100 times more common), PSC is the fourth leading indication for liver transplantation in the U nited States $(15,16)$. Its association with ulcerative colitis (occurring in up to $7 \%$ of patients with ulcerative colitis $[15,16])$, has prompted numerous immunological theories regarding the pathogenesis of PSC, but its etiology remains obscure $(17,18)$.

Endoscopic retrograde cholangiopancreatography (ERCP) became widely available in the 1970s and has subsequently evolved as an important diagnostic and therapeutic tool in the management of hepatobiliary and pancreatic diseases. Reports of percutaneous management of strictures in PSC $(19,20)$ were followed by successful reports of endoscopic intervention beginning in 1987 (19-21). ERCP has become the 'gold standard' for diagnosing this disorder. Therapeutic ERCP has added another layer of complexity to the management of patients with PSC. Published case series have documented successful endoscopic management of PSC with dominant strictures $(10,22-28)$. U nfortunately, as with many reports regarding endoscopy, control groups are often not identified, complication rates vary widely and long term follow-up is sadly lacking. Furthermore, improvement in liver enzymes following therapeutic intervention is stressed as a positive outcome. Because the natural history of PSC is one of fluctuating liver serology associated with recurrent exacerbation and remission of symptoms, data from a suitable control group (patients with PSC undergoing diagnostic ERCP) are necessary before concluding that any therapeutic intervention has been successful.

For these reasons we have reviewed our own experience of endoscopy in patients with PSC. The specific objectives of the study were to document and compare the liver profile and clinical status of patients before and after diagnostic and therapeutic ERCP; to determine predictors of clinical and laboratory success in patients with PSC; and to assess the complication rate of diagnostic and therapeutic ERCP in these patients. The present study builds on our previous experience (28) with an attempt to incorporate data on appropriate patient selection for ERCP in the setting of PSC.

\section{METHODS}

A II patients with PSC who underwent ERCP between January 6 , 1987 and January 12, 1998 were evaluated. A II ERC Ps performed at Duke U niversity M edical C enter, U SA during this period were recorded in a commercially available computerized database ( $\mathrm{GI}$ TRA C 1.0 and 2.0 [A kron Systems, USA ]). A ppropriate patients were identified by conducting a search of the database using the diagnosis sclerosing cholangitis as the search parameter. A II biliary service records were subsequently reviewed for possible inclusion in the analysis. O nly patients with primary sclerosing cholangitis were included within the study group; those with secondary sclerosing cholangitis (eg, acquired immunodeficiency syndrome cholangiopathy, oriental cholangiohepatitis, drug-related, ischemic) were excluded. Patients were identified as being in diagnostic and therapeutic groups. Diagnostic ERCPs were strictly defined as those without therapeutic intervention. Therapeutic biliary interventions included sphincterotomy, stent insertion, stricture dilation, nasobiliary tube insertion or a combination of the above. Therapeutic procedures were performed as previously described (28). A lthough nasobiliary tube insertion does not significantly alter the physical characteristics of a strictured biliary tree, the fact that it bridges strictures and may be used for irrigation led it to be identified as a therapeutic procedure.

Data collected from each patient's record included sex, race, age, date of procedure, type and duration of symptoms, duration of disease, associated disease (eg, C rohn's disease, ulcerative colitis), presence and location of dominant stricture and preoperative and postoperative liver serology. Specific indications for ERCP in PSC included jaundice, fever, pruritus, abdominal pain, asymptomatic elevation in liver enzymes and follow up of previous therapy. In patients in whom there were multiple indications for ERCP, the most prominent indication was selected as the primary reason for the procedure and the others were numbered in order of severity. Complications of ERCP were classified as mild (zero to four days in hospital), moderate (five to nine days in hospital) or severe (10 or more days in hospital), according to the classification of $\mathrm{C}$ otton (29). Early complications were collected by reviewing the ERCP 


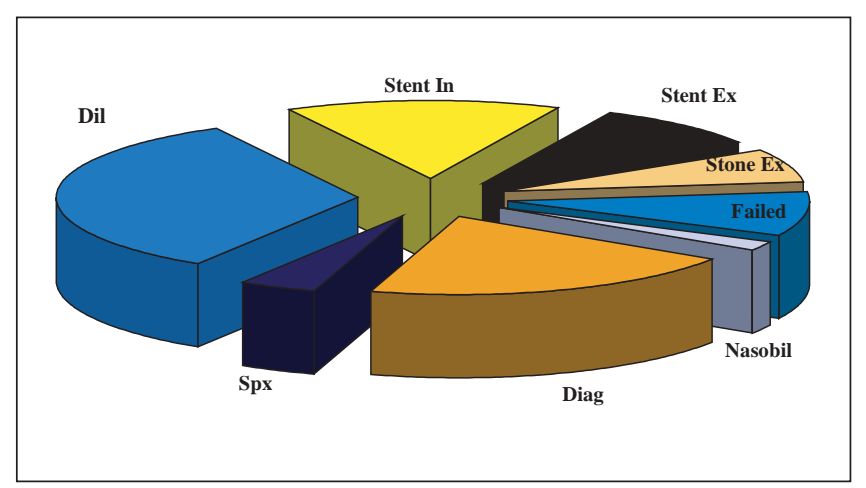

Figure 1) Endoscopic retrograde cholangiopancreatography (ERCP) and therapy performed. Two hundred four ERC Ps in 104 patients with primary sclerosing cholangitis. Diagnostic procedures in 56 and therapeutic in 148 cases (including 25 partially successful or failed procedures). $N$ ote: Sixty-seven patients undergoing ERC $P$ had more than one therapeutic intervention during one procedure. Diag Diagnostic study alone; Dil Balloon or step dilation; Failed Partial or unsuccessful procedure; N asobil N asobiliary tube insertion; Spx Sphincterotomy Stent Ex Stent extraction; Stent In Stent insertion; Stone Ex Stone extraction

report and hospital records. Late complications were assessed through follow-up visits as well as through ongoing correspondence with referring physicians. The type and severity of each complication were recorded for all procedures.

\section{D efinitions of success}

The success of ERCP in sclerosing cholangitis was defined in two separate parameters. 'Clinical success' was defined as the resolution of the primary presenting symptom that initiated the investigations. In patients with multiple presenting symptoms, the most prominent symptom was selected. In most patients, the presenting symptom and the indication for the procedure were identical. Because of known fluctuations in serum liver enzymes in stable patients with PSC, 'Iaboratory success' was defined as an improvement in two liver enzymes (aspartate aminotransferase, alanine aminotransferase or alkaline phosphatase) by greater than $50 \%$, or resolution of jaundice. Serum liver enzyme levels were determined before the ERCP and approximately three to six months later. When possible, follow-up liver enzymes were analyzed when the patient was clinically stable. Data relating to failed or incomplete procedures were also noted and recorded.

\section{Statistical analysis}

All statistical analyses were performed using the Statistical A nalysis System (SA S, U SA) software version 6.12. Continuous variables were expressed as means and standard deviations, or medians and interquartile ranges (IQR: 25th to the 75th percentiles) if the data were not normally distributed. Dichotomous variables were expressed as percentages. 0 dds ratios (ORs) and $95 \% \mathrm{Cl}$ were calculated to compare complications rates in patients undergoing therapeutic and diagnostic ER C P. C ategorical variables were compared with either the $\chi^{2}$ or Fisher's exact test. Continuous variables were compared using the Wilcoxon rank sum test or the t test, when indicated. C hanges of liver enzyme levels were compared using a paired t test or W ilcoxon sign rank test if the data were not normally distributed. U nivariate and multivariate logistic regression were performed to determine the association between the independent variables (age, sex, race, liver
TABLE 1

Therapeutic and diagnostic endoscopic retrograde cholangiopancreatography (ERCP) groups: Baseline comparison

\begin{tabular}{lccc}
\hline & $\begin{array}{c}\text { Diagnostic } \\
(\mathbf{n}=56)\end{array}$ & $\begin{array}{c}\text { Therapeutic } \\
(\mathbf{n}=\mathbf{1 2 3})\end{array}$ & $\mathbf{P}$ \\
\hline Age (years) & $44.5 \pm 15.3$ & $44.8 \pm 12.5$ & $0.85^{\star}$ \\
Sex (male/female) & $32 / 24$ & $77 / 46$ & $0.48^{\dagger}$ \\
$\begin{array}{l}\text { Presence of IBD (\%) } \\
\text { Duration of disease }\end{array}$ & $45(25 / 56)$ & $62(69 / 123)$ & $0.16^{\dagger}$ \\
$\quad$ (months) & & & $0.12^{\ddagger}$ \\
Duration of symptoms & $1(\mathrm{IQR} 7.5-75)$ & $36(\mathrm{IQR} 17-68)$ & \\
$\quad$ (weeks) & & & $0.80^{\star}$ \\
Per cent presenting with: & & & \\
$\quad$ Fever & $16 \%(9 / 56)$ & $30 \%(37 / 123)$ & $0.05^{\dagger \S}$ \\
$\quad$ Pain & $18 \%(10 / 56)$ & $23 \%(28 / 123)$ & $0.45^{\dagger}$ \\
Jaundice & $25 \%(14 / 56)$ & $32 \%(39 / 123)$ & $0.36^{\dagger}$ \\
\hline
\end{tabular}

* test; ${ }^{+} \chi^{2}$ test; ${ }^{\ddagger}$ Wilcoxon Rank Sum test; $\$$ Significant difference. IBD Inflammatory bowel disease; IQR Interquartile ranges

enzymes, presenting symptoms, the presence and location of a stricture) and the outcome of interest (success). Separate models were evaluated to determine the predictors of clinical and laboratory success. OR and $95 \% \mathrm{CI}$ were computed from the estimated coefficients in the logistic regression. A II $P$ values were two sided, with $\alpha=0.05$ as the standard for significance.

\section{RESU LT S}

Two hundred four procedures were performed on 104 patients with the diagnosis of PSC. Therapeutic procedures were attempted in 148 cases and diagnostic ERCP alone in 56. The most common biliary therapeutic interventions (Figure 1) were stricture dilation $(40 \%)$, stent insertion (19.6\%), stent extraction (12.3\%) and stone extraction (9.3\%). The therapeutic intervention was considered unsuccessful or incomplete in 25 (12.3\%) ERCPs; therefore, these were excluded from the final analysis. The mean age of the patients was $45 \pm 13.6$ years old; $63 \%$ of the patients were male and $78.9 \%$ were white. The most common presenting complaints were fever $(25.5 \%)$, pain (23\%) and jaundice (17\%). The median duration of symptoms was seven days (IQR 2.9 to 21 ) and the median duration of disease was 36 weeks (IQR 12 to 71).

The predominant stricture location was the common bile duct (CBD) in $34 \%$ of the patients. The common hepatic duct was affected in $20 \%$ of patients, the hilum in $11 \%$ and the intrahepatic biliary tree in $35 \%$. M ost patients with intrahepatic disease had diffuse small duct involvement not amenable to endoscopic intervention. In $66 \%$ of the patients, however, a dominant stricture was identified.

W hen the therapeutic and diagnostic groups were compared (Table 1), they were found to be similar in all categories except the percentage of patients presenting with fever, in which the two groups differed significantly ( $P=0.05)$. The two groups were subsequently compared in three parameters: clinical success after ERCP, laboratory success after ERC $P$ and complications of the procedure.

\section{Clinical}

O verall, $52.9 \%$ of the patients had resolution of their presenting complaints, maintained at three to six months, which met the criteria for clinical success. Clinical improvement was seen in 35\% of the patients after diagnostic ERCP and in $70 \%$ of the patients after therapeutic ERCP (P=0.0001) (Figure 2). Clinical success after 


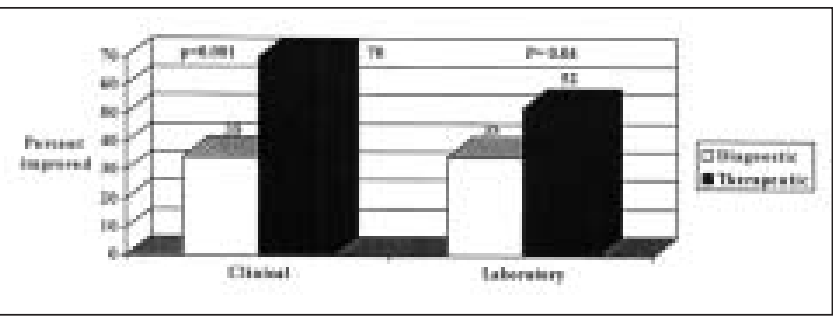

Figure 2) C linical and laboratory success rates after diagnostic and therapeutic endoscopic retrograde cholangiopancreatography groups in primary sclerosing cholangitis

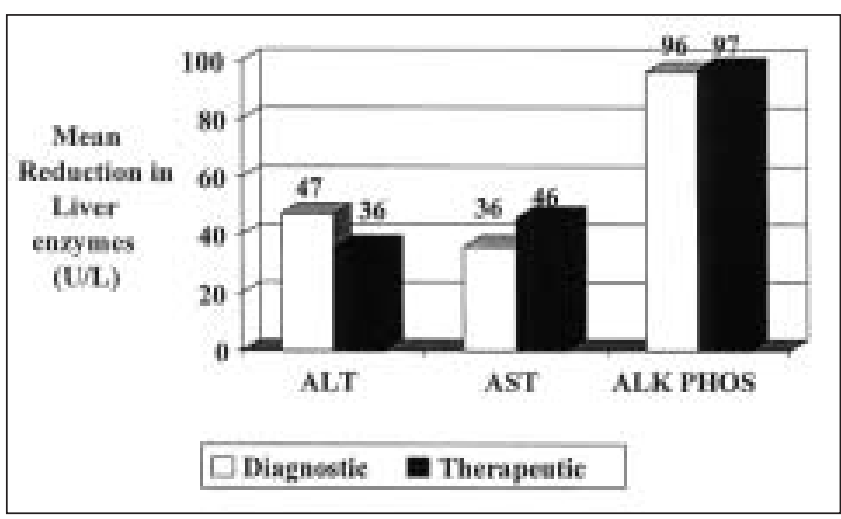

Figure 3) C hange in serum liver enzyme levels before and after diagnostic and therapeutic endoscopic retrograde cholangiopancreatography groups. ALT Alanine aminotransferase; Alk Phos Alkaline phosphatase; A ST A spartate aminotransferase

therapeutic procedures was greater for CBD strictures (73.7\%) than for common hepatic duct strictures $(63.0 \%)$. A lthough there were only 18 patients in whom therapeutic invention was attempted for dominant hilar strictures, clinical success was attained in 13 $(72.2 \%)$. In select patients with dominant strictures occurring in main intrahepatic ducts, endoscopic therapy was successful in $63.2 \%$ (12 of 19). Interestingly, considerable success in treating clinical symptoms was achieved in the diagnostic group, with $35 \%$ of patients having resolution of their presenting complaint. M ost of these patients (84\%) had intrahepatic disease not amenable to therapeutic intervention. Patients undergoing therapeutic endoscopy were more likely to have clinical improvement in symptoms of fever $(82.4 \%)$ and pruritus (80\%) than jaundice $(48.3 \%)$.

\section{L aboratory}

O verall, laboratory success occurred in $41.2 \%$ of patients. Improvement was seen in $52.1 \%$ of patients undergoing a therapeutic procedure and in $35.3 \%$ of patients having a diagnostic one $(P=0.04)$ (Figure 2$)$. Laboratory success rates for therapeutic procedures were highest in patients with distal biliary strictures; $59.5 \%$ of patients with CBD or common hepatic duct strictures, but only in $36.8 \%$ of patients with hilar or intrahepatic strictures $(P=0.022)$. In patients who underwent therapeutic endoscopy, those with common duct strictures were 2.5 times more likely to have clinical success than those patients with hilar and intrahepatic strictures ( $95 \% \mathrm{Cl}, 1.13$ to 5.6$)$. In patients undergoing diagnostic procedures, $62.5 \%$ of those with common duct strictures and $30.2 \%$ of those with intrahepatic strictures had improvement in liver serology. H owever, because of small numbers in the CBD

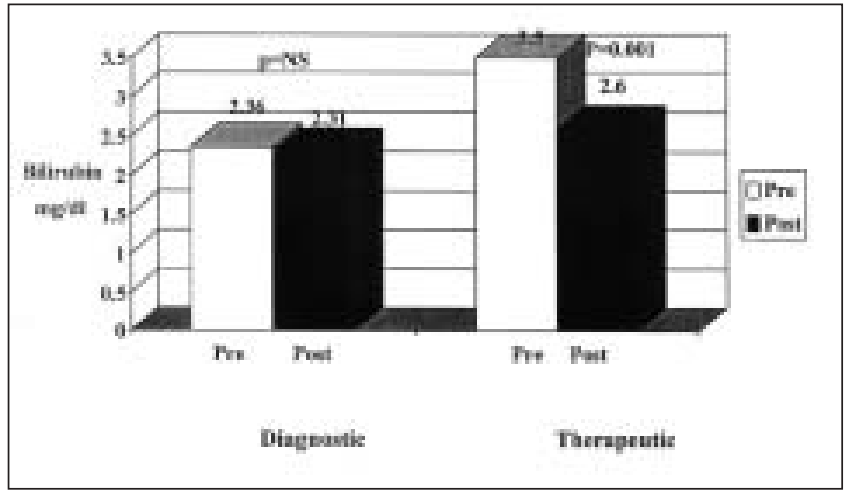

Figure 4) M ean serum bilirubin level before and after diagnostic and therapeutic endoscopic retrograde cholangiopancreatography

stricture group ( $n=8)$, the differences as analyzed by Fisher's Exact Test were not significant $(P=0.112)$.

$M$ ean preprocedure levels of serum liver enzymes were similar in the therapeutic and diagnostic groups. A lthough the most significant improvements in serum transaminases were seen in the therapeutic ERCP group, diagnostic ERCP also resulted in significant reductions in alanine aminotransferase, aspartate aminotran sferase and alkaline phosphatase ( Figure 3). C hanges in serum bilirubin before and after ERCP were only significant in the therapeutic group. Despite this, the mean serum bilirubin level after therapeutic ERCP was still elevated at $2.6 \mathrm{mg} / \mathrm{dL}$ (SD 4.24) (Figure 4).

\section{Predictors of success}

In a univariate analysis, patients with a dominant biliary stricture were more likely to have a successful clinical outcome (Table 2) than those without ( $O R=3.73,95 \% \mathrm{Cl}, 1.95$ to 7.13). In addition, patients with a CBD stricture were more likely to have a successful clinical outcome than those with other stricture locations ( $O R=2.47,95 \% \mathrm{Cl}, 1.27$ to 4.81 ). Endoscopic therapy was an independent determinant of clinical success $(O R=4.23 .95 \% \mathrm{Cl}$, 2.15 to 8.34 ). Similar outcomes are found when analyzing laboratory improvement in patients with PSC undergoing ERCP (Table 2). In multivariable logistic regression (Table 3 ), the presence of a dominant stricture, endoscopic therapy and a high serum bilirubin level were all independent predictors of a successful clinical outcome $\left(\chi^{2}=26.7\right.$ with three degrees of freedom, $P=0.0001$ ). In a separate model, the presence of a dominant stricture, a CBD stricture and endoscopic therapy were all independent predictors of a successful laboratory outcome $\left(\chi^{2}=8.32\right.$ with three degrees of freedom, $\mathrm{P}=0.03$ ).

\section{Complications}

Thirty-four complications (17\%) resulting in hospital admission lasting longer than $24 \mathrm{~h}$ occurred in 30 patients undergoing 33 ERCPS. O ne patient suffered two complications of a single ERCP. Despite prophylactic administration of broad spectrum antibiotics, cholangitis occurred in 15 patients (7.5\%). M ost cases of cholangitis were mild but two patients had complicated infections requiring hospital stays longer than 10 days. One of these patients developed a hepatic abscess that was managed surgically. Pancreatitis was the next most common complication, occurring in 10 patients (5\%) with four having severe pancreatitis. Bile duct injuries (contained biliary leaks) were noted in two patients; both 
TABLE 2

Results of a univariate analysis of clinical and laboratory success

\begin{tabular}{lccc}
\hline Outcome & $\begin{array}{c}\text { Location of a } \\
\text { stricture* }^{\star}\end{array}$ & $\begin{array}{c}\text { Presence of a } \\
\text { dominant stricture }\end{array}$ & $\begin{array}{c}\text { Endoscopy } \\
\text { therapy }\end{array}$ \\
\hline Clinical success & $2.47(1.27-4.81)$ & $4.23(2.15-8.34)$ & $3.73(1.95-7.13)$ \\
Laboratory success & $2.03(1.07-3.87)$ & $1.99(1.012-3.94)$ & $2.46(1.27-4.78)$
\end{tabular}

${ }^{*}$ Common bile duct compared with all other locations. Data is presented as $\mathrm{OR}(\mathrm{Cl})$

were managed without surgical intervention but one required hospital admission for greater than 10 days. $\mathrm{N} o$ deaths occurred in the study group.

A Ithough there was a trend toward a slightly higher complication rate in the therapeutic ERCP group $(18 \%, 27$ of 148), this was not statistically different from the diagnostic group (14\%, eight of 56). However, statistical differences were seen in the subgroup analysis of severity of complications; all seven severe complications occurred in the therapeutic group. These included one bile duct injury, one hepatic abscess, four cases of pancreatitis and one of cholangitis.

\section{DISC U SSION}

PSC is a progressive disorder for which liver transplantation is the final therapeutic option in select patients $(6,12,13,30)$. The role of ERCP as a diagnostic tool is well established, but its use for therapy should be selective because not all patients will benefit. Published series have documented impressive success rates for therapeutic ERCP in select groups of patients with PSC $(10,22,24,25,27,28,31)$. Despite the positive outcomes of these analyses, only one included a control group (28). We have attempted to compare a control group (PSC patients undergoing diagnostic ERCP) and a therapeutic group to determine whether successes reported in previous studies were likely to have been secondary to the intervention and not to another confounding variable. In an ideal world, criteria would be available before the ERCP to predict which patients with PSC may benefit from a therapeutic procedure, thereby avoiding unhelpful or even dangerous interventions.

In this analysis, approximately twice as many patients had clinical improvement following therapeutic ERCP than after a diagnostic study. Interestingly, 35\% of patients who did not have a therapeutic intervention still showed clinical improvement following diagnostic ERCP. The reasons for this are unclear. One possible explanation would attribute this improvement to the characteristic fluctuating nature of the disease; ie, 'chance' improvement at times of clinical reassessment. H owever, many of these patients had rapid improvement following hospital admission. Perhaps a treatment received in hospital improved the results of ERCP? The most likely candidate is routine antibiotic prophylaxis. We routinely administer an intravenous penicillin and an aminoglycoside (or a cephalosporin alone in penicillin-allergic patients) before ERCP when PSC is known or suspected. Following the procedure, hospitalized patients are usually given a minimum of $24 \mathrm{~h}$ of parenteral antibiotic therapy, or longer if there is any evidence of sepsis. 0 utpatients go home after uncomplicated procedures but we provide them with up to 10 days of the oral quinolone antibiotic, ciprofloxacin, to reduce the risk of postprocedure cholangitis. A ntibiotic therapy may contribute to the clinical improvement seen in some PSC patients undergoing diagnostic ERCP and, therefore, should be used in all patients with PSC undergoing ERCP.
TABLE 3

Results of the logistic regression model for clinical success predictors

\begin{tabular}{lccc}
\hline Variable & Odds ratio & $\mathbf{9 5 \%} \mathbf{C l}$ & $\mathbf{P}$ \\
\hline Dominant stricture & 2.40 & $1.00-5.79$ & 0.04 \\
Bilirubin & 0.9 & $0.83-097$ & 0.009 \\
Endoscopic therapy & 2.614 & $1.06-6.45$ & 0.03 \\
\hline
\end{tabular}

O ur therapeutic results are consistent with the clinical improvement in PSC patients documented by van Milliegen de W it et al (25), where $76 \%$ of a highly select group of 21 patients with PSC improved after their strictures were stented. Lee et al (28) found that $53 \%$ of patients undergoing therapeutic ERCP improved clinically but only $23 \%$ of patients improved following a diagnostic procedure. Wagner et al (24) noted a $67 \%$ clinical improvement following aggressive endoscopic intervention. Gaing et al (22) noted that all 16 PSC patients they treated therapeutically experienced immediate improvement of their symptoms (pain, fever and jaundice), although five suffered recurrent cholangitis and multiple hospital admissions during the follow-up period. In our analysis these outcomes would not have been considered clinical successes. There is evidence that hospitalizations and future episodes of cholangitis are decreased by endoscopic therapy (27). W e did not specifically evaluate these outcomes, but in our study if the indication for the therapeutic ERCP was cholangitis and the patient had documented episodes of cholangitis during a three to six month follow-up, then this was not considered a clinical success.

Laboratory parameters following ERC $P$ in PSC patients have been evaluated in several studies. In most published series liver tests have improved. In some studies only serum bilirubin $(22,27)$ or alkaline phosphatase improved (22). In contrast, an eight-year prospective trial of therapeutic ERCP (dilation of dominant strictures) used in combination with oral ursodeoxycholic $(n=65)$ did not change bilirubin levels significantly (10). O nly Lee et al (28) compared laboratory parameters with a control group of patients who also underwent ERCP in a diagnostic manner. Our results demonstrate that transaminases and alkaline phosphatase improve in both the diagnostic group and the therapeutic group. The likely explanation for this lies in the fact that all patients receive antibiotics before and after the procedure. This is routinely done in patients with cholangitis as a treatment and in others as a prophylactic measure against ascending cholangitis before ERCP. A Ithough most studies of therapeutic ERCP for PSC have shown an improvement in serum bilirubin levels, these do not necessarily return to normal. Despite improved laboratory values, the patient often still has a mildly elevated serum bilirubin reflecting incomplete bile drainage (often of small bile ducts), compromised hepatic cellular function or both. In our analysis, the mean bilirubin dropped significantly, from $3.5 \mathrm{mg} / \mathrm{dL}$ to $2.6 \mathrm{mg} / \mathrm{dL}$ after therapeutic ERCP. This was different from the experience in the diagnostic group, where no change in bilirubin level was noted. Serum bilirubin has been shown consistently to be an important predictor of survival $(32,33)$. Despite improvement in liver enzymes in the diagnostic group, the serum bilirubin only improved after therapeutic intervention in our study, perhaps indicating amelioration of disease severity.

There has been extensive discussion regarding radiological improvement of PSC strictures in the past $(24,27,28)$. If a biliary stricture appears radiologically improved, then it is logical to assume that bile flow will also improve. U nfortunately, stricture 
appearances do not necessarily correlate with clinical and laboratory findings in PSC. For this reason, we did not specifically review stricture changes in our analysis.

A lthough lacking the sensitivity and specificity of ERCP, abdominal ultrasound (34) and computerized tomography can be used to exclude other disorders that may mimic PSC. Early reports indicate excellent diagnostic capabilities of magnetic cholangiopancreatography (MRCP) in PSC (35). If we could predict which patients were unlikely to benefit from ERC $P$, they could be selected for noninvasive imaging, such as M RCP. We sought to delineate a group of patients most likely to benefit from ERCP. A ge, duration of disease and symptoms, type of symptoms, sex and race were found not to be important predictors of success after ERCP in patients with PSC. Patients with CBD strictures were approximately twice as likely to have clinical and laboratory improvement after ERCP as those without. A s intrahepatic disease is generally not amenable to endoscopic therapy, the group of patients with predominantly intrahepatic PSC could be managed without ERC P if the diagnosis was suspected ahead of time. The

\section{REFEREN CES}

1. M ajoie $C B$, H uibregtse $K$, Lehman $G$. Primary sclerosing cholangitis. A bdom Imaging 1997;22:194-8.

2. W iesner RH. Current concepts in primary sclerosing cholangitis. M ayo Clin Proc 1994;69:969-82.

3. Lee YM, Kaplan M M . Primary sclerosing cholangitis. N Engl J M ed 1995;332:924-33.

4. Weisner RH, LaRusso N F. C linicopathological features of the syndrome of primary sclerosing cholangitis. G astroenterology 1980;79:200-6.

5. Stiehl A. U rsodeoxycholic acid in the treatment of primary sclerosing cholangitis. A nn M ed 1994;26:345-9.

6. H arrison J, M cM aster P. The role of orthotopic liver transplantation in the management of sclerosing cholangitis. Hepatology 1994;20:14S-19S.

7. Klompmaker II, H aagsma EB, Verwer R, Jansen PL, Sloofe MI. Primary sclerosing cholangitis and liver transplantation. Scand J G astroenterol Suppl 1996;218:98-102.

8. Stiehl A. U rsodeoxycholic acid therapy in treatment of primary sclerosing cholangitis. Scand J G astroenterol Suppl 1994;204:59-61.

9. Van de M eeberg PC, van Erpecum KJ, van Berge-H enegouwen GP. Therapy with ursodeoxycholic acid in cholestatic liver disease. Scand J Gastroenterol Suppl 1993;200:15-20.

10. Stiehl A, Rudolph $G$, Sauer $P$, et al. Efficacy of ursodeoxycholic acid treatment and endoscopic dilation of major duct stenoses in primary sclerosing cholangitis: A n 8-year prospective study. J H epatol 1997;26:560-6.

11. Van de M eeberg PC, W olfhagen FH, van Erpecum KJ, van Berge $\mathrm{H}$ enegouwen G P. C holestatic liver diseases: N ew strategies for prevention and treatment of hepatobiliary and cholestatic diseases. N eth J Med 1995;47:30-5

12. Kilpe VE, Krakauer $H, W$ ren RE. A $n$ analysis of liver transplant experience from 37 transplant centers as reported to M edicare. Transplantation 1993;56:554-61.

13. A bu Elmagd KM, M alinchoc M, Dickson ER, et al. Efficacy of hepatic transplantation in patients with primary sclerosing cholangitis. Surg Gynecol Obstet 1993;177:335-44.

14. Chazouilleres 0, Poupon R, Capron JP, et al. U rsodeoxycholic acid for primary sclerosing cholangitis. J Hepatol 1990;11:120-3.

15. Galambos JT. Epidemiology of al coholic liver disease: U nited States of A merica. In: H all P, ed. A Icoholic Liver Disease: Pathobiology, Epidemiology and Clinical A spects. N ew York: John W iley, 1985:230-49.

16. G aragliano C F, Lilenfeld A M, M endel off A I. Incidence rates of liver cirrhosis and related diseases in Baltimore and selected areas of the United States. J Chronic Dis 1979;32:543-54.

17. van M illigen de W it AW, van Deventer SJ, Tytgat G N . Immunogenetic aspects of primary sclerosing cholangitis: Implications for therapeutic strategies. A m J G astroenterol 1995;90:893-900.

18. Boberg KM, Lundin KE, Schrumpf E. Etiology and pathogenesis in primary sclerosing cholangitis. Scand J G astroenterol Suppl 1994;204:47-58. likelihood of a successful outcome of ERCP in PSC is inversely related to the serum bilirubin level. Although the bilirubin will usually decrease following a therapeutic procedure, very high serum bilirubin levels are unlikely to normalize, reflecting chronic hepatocellular damage and impaired bile flow. This is another group of patients who may benefit from a noninvasive test to clarify stricture location.

\section{CONCLUSIONS}

ERC P plays an important role in the diagnosis and management of PSC. Complication rates appear to be higher than after ERC P performed for other indications. Serum transaminases and alkaline phosphatase levels improve following both therapeutic and diagnostic ERCP, possibly secondary to an antibiotic effect. Because bilirubin improved only after therapeutic ERCP and it is known to be a marker for survival in PSC, it may be the best marker to denote success after a therapeutic procedure. 0 nce validated studies of MRCP become available, it may be a useful diagnostic screening tool before considering ERCP in patients with PSC.

19. Martin EC, Fankuchen El, Schultz RW, Casarella W J. Percutaneous dilation in primary sclerosing cholangitis. A m J Roentgenol 1981;137:603-5.

20. Vogel SB, H oward RJ, C aridi J, H awkins IF. Evaluation of percutaneous transhepatic balloon dilation of benign biliary strictures in high risk patients. A m J Surg 1985;149:73-9.

21. Cairns SR, C otton PB. Potential for endoscopic therapy for primary sclerosing cholangitis. G ut 1987:28:A 1342.

22. Gaing A A, G eders JM, C ohen SA, Siegel JH. Endoscopic management of primary sclerosing cholangitis: Review, and report of an open series. A m J G astroenterol 1993;88:2000-8.

23. Deviere J. Therapeutic endoscopy and primary sclerosing cholangitis. Endoscopy 1996;28:576-7.

24. Wagner S, G ebel M, M eier P, et al. Endoscopic management of biliary tract strictures in primary sclerosing cholangitis. Endoscopy 1996:28:546-51.

25. van M illigen de W it AW, van Bracht J, Rauws EA, Jones EA, Tytgat GN , H uibregtse K. . Endoscopic stent therapy for dominant extrahepatic bile duct strictures in primary sclerosing cholangitis. G astrointest Endosc 1996;44:293-9.

26. Cotton PB, N ickl N. Endoscopic and radiologic approaches to therapy in primary sclerosing cholangitis. Semin Liver Dis 1991;11:40-8.

27. Johnson GK, G eenen JE, Venu RP, Schmalz MJ, H ogan WJ. Endoscopic treatment of biliary tract strictures in sclerosing cholangitis: A larger series and recommendations for treatment. $G$ astrointest Endosc 1991;37:38-43.

28. Lee JG, Schutz SM, England RW, Leung JW, Cotton PB. Endoscopic therapy of sclerosing cholangitis. H epatology 1995;21:661-7.

29. Cotton PB, Lehman G, Vennes], et al. Endoscopic sphincterotomy complications and their management: A $n$ attempt at consensus. G astrointest Endosc 1991:37:383-93.

30. Eckhauser FE, C olleti LM, Knol JA. The changing role of surgery for sclerosing cholangitis. Dig Dis 1996;14:180-91.

31. Lombard M, Farrant M, Karani J, W estaby D, W illiams R. Improving biliary-enteric drainage in primary sclerosing cholangitis: Experience with endoscopic methods. G ut 1991;32:1364-8.

32. W iesner RH, G rambsch PM, Dickson ER, et al. Primary sclerosing cholangitis: N atural history, prognostic factors and survival analysis. H epatology 1989;10:430-6.

33. Farrant JM, Hayllar KM , W ilkinson $M L$, et al. $\mathrm{N}$ atural history and prognostic variables in primary sclerosing cholangitis. $G$ astroenterology 1991;100:1710-7.

34. Majoie C B, Smits NJ, Phoa SS, Lehman G, Jansen PL. Primary sclerosing cholangitis: Sonographic findings. A bdom Imaging 1995;20:109-12.

35. Ernst O, A sselah T, Talbodec N, Sergent G. M R cholangiopancreatography: A promising new tool for diagnosing primary sclerosing cholangitis. A m J Roentgenol 1997;168:1115-6. (Lett) 


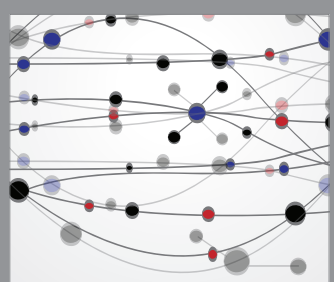

The Scientific World Journal
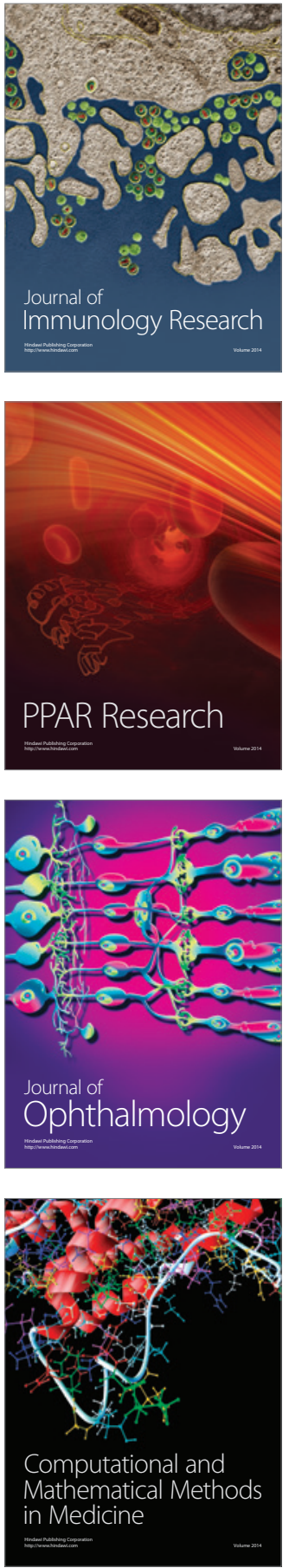

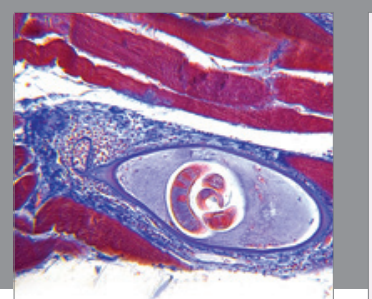

Gastroenterology Research and Practice

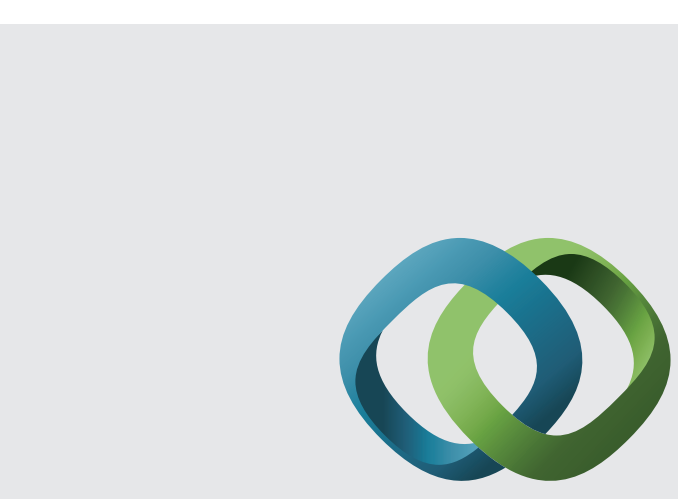

\section{Hindawi}

Submit your manuscripts at

http://www.hindawi.com
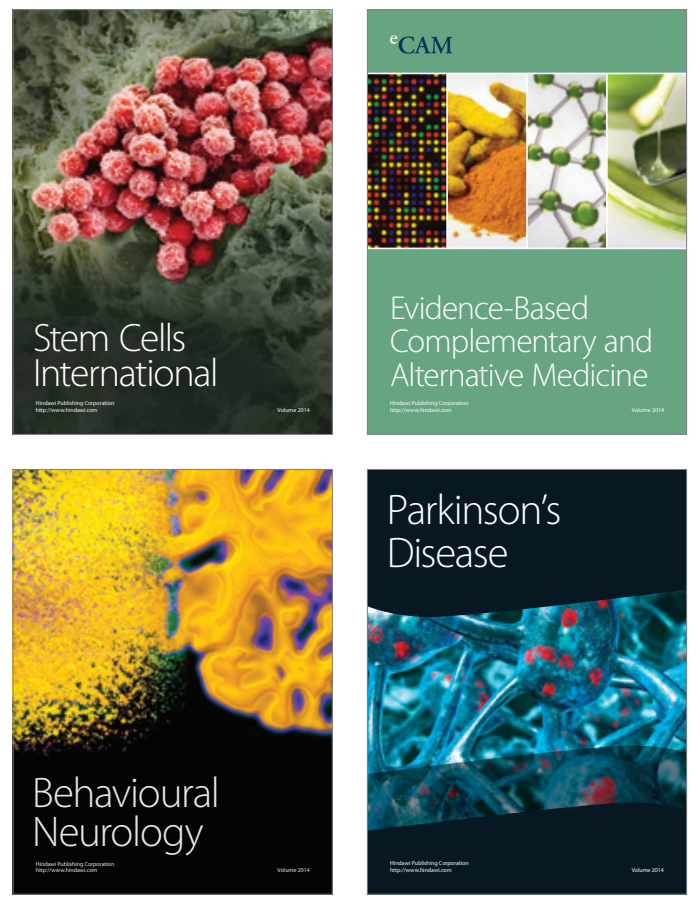
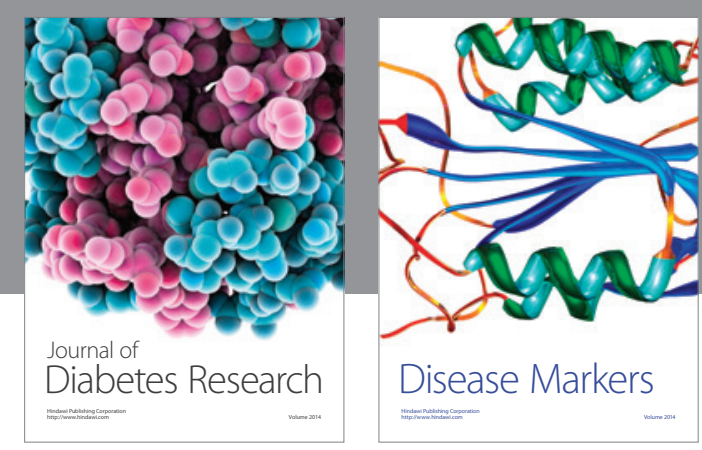

Disease Markers
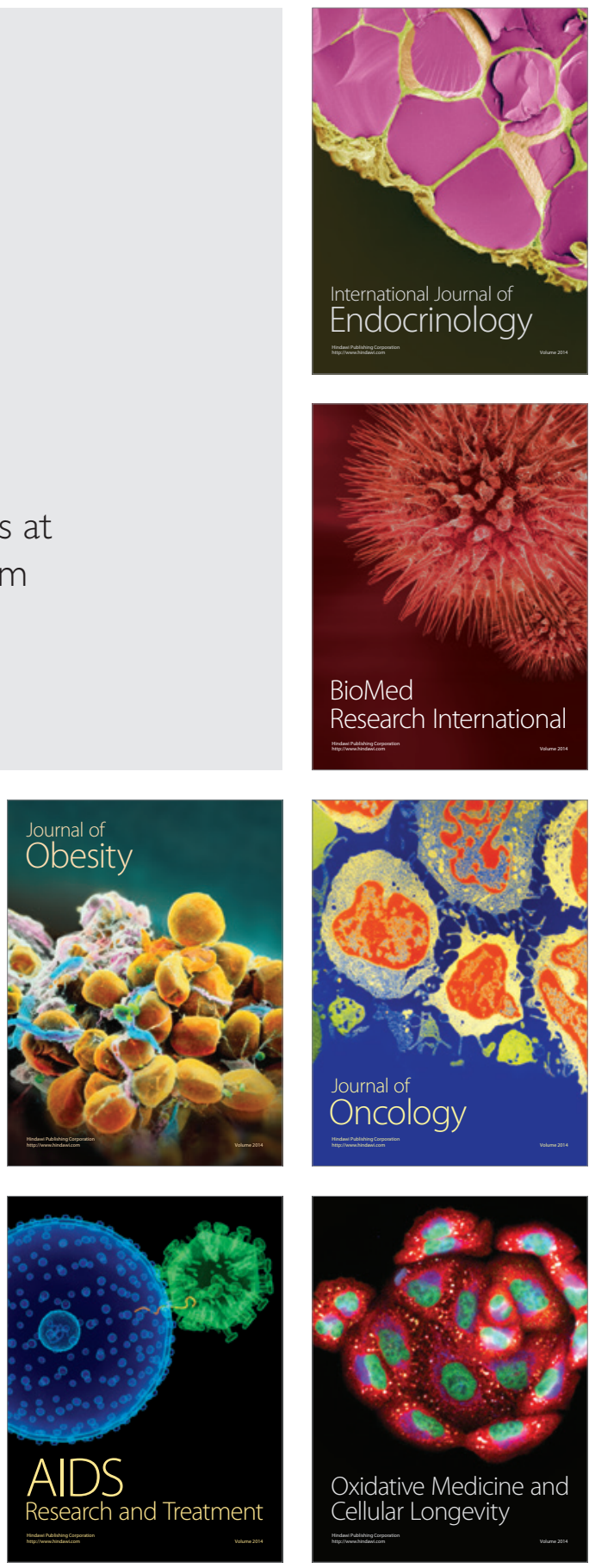